\title{
ANALISIS FAKTOR DOMINAN YANG MENGAKIBATKAN PEMBENGKAKAN BIAYA OLEH KONTRAKTOR PADA PROYEK JALAN KABUPATEN WONOGIRI APBD TAHUN 2017 DAN 2018
}

\author{
Muhammad Nur Sahid ${ }^{1)}$, Anto Budi Listyawan ${ }^{2)}$, Abdul Rochman ${ }^{3)}$, dan Rim Dzaky Haidar ${ }^{4)}$ \\ ${ }^{1,2,3)}$ Dosen Jurusan Teknik Sipil FT UMS, Jl. Ahmad Yani, Pabelan, Kartasura, Surakarta \\ 4) Mahasiswa Teknik Sipil FT UMS \\ Jl. Ahmad Yani, Pabelan, Kartasura, Surakarta
}

\begin{abstract}
The implementation of the road project in Wonogiri Regency was often different between the planning with has be held that making problem for contractor like as late work and cost overrun. Therefore, the purpose of this research is knowing what is cost overrun factors and also amount of cost overruns of the road project in Wonogiri Regency which used APBD 2017 and 2018 experienced by contractor. This research was conducted by asking questions to the contractor who worked on the road project in 2017 and 2018. The analysis of this research has using the SPSS program. Based on the analyis has been done, field regulation become dominant of cost overrun. The lack of provision of field support facilities and the limited size of the project area are the reasons why field regulation factors can be a major factor causing cost overruns on road projects in Wonogiri Regency. Based on the answers from respondents it can be concluded that the contractors who experienced a swelling cost of $1 \%-5 \%$ there were 44 respondents, then for the cost swelling of $6 \%-10 \%$ there were 28 respondents, and $11 \%-15 \%$ there were 2 respondents, and $16 \%-20 \%$ only 1 respondent.
\end{abstract}

Key Words: cost, cost overrun, dominant factor

\section{PENDAhUluan}

Majunya suatu negara ditandai dengan pembangunan yang merata. Salah satu pembangunan tersebut adalah pembangunan pada bidang infrastruktur. Pembangunan itu sendiri ada bermacam-macam, diantaranya pembangunan gedung, jalan, jembatan, bendungan, dan lain-lain. Jalan merupakan sistem transportasi yang mempunyai peranan penting, yaitu menghubungkan antarwilayah. Jalan juga mempunyai peranan penting di berbagai bidang. Jalan digunakan untuk sarana transportasi darat yang berfungsi untuk memberikan layanan kepada pengguna. Jalan adalah infrastruktur sipil yang dilakukan untuk menggunakan alam supaya bermanfaat untuk manusia. Tentunya pembangunan itu tidak terlepas dari suatu masalah. Masalah yang sering dialami adalah kesesuaian waktu dan biaya. Realisasi waktu dan biaya seringkali tidak sesuai dengan rencana, sehingga manajemen dibutuhkan untuk memecahkan permasalahan ini.

Kabupaten Wonogiri merupakan daerah dengan luas wilayah 182.236,02 ha, ini merupakan wilayah terluas di Karesidenan Surakarta. Wonogiri adalah kawasan dengan topografi daerah yang tidak rata, perbedaan antara satu kawasan dengan kawasan lain membuat kondisi sumber daya alam juga saling berbeda. Hampir sebagian besar tanahnya tidak terlalu subur untuk pertanian, bebatuan, dan kering sehingga membuat penduduknya lebih banyak merantau (UU No. 13/1950 (19 Mei 1741)).

Kabupaten Wonogiri belakangan ini banyak melaksanakan pembangunan, salah satunya pembangunan jalan. Pada proyek pembangunan jalan tersebut tentunya tidak terlepas dari suatu masalah. Masalah yang sangat berisiko adalah masalah biaya.

Penelitian ini bertujuan untuk mengetahui faktor apakah yang mengakibatkan pembengkakan biaya (cost overrun) dan juga besarnya pembengkakan biaya pada proyek jalan di Kabupaten Wonogiri yang menggunakan APBD pada tahun 2017 dan 2018 yang dialami oleh para kontraktor.

Penelitian ini dapat memberikan manfaat kepada beberapa pihak. Untuk kontraktor, hasil penelitian yang dilakukan dapat mencegah terjadinya pembengkakan biaya pada proyek jalan yang berada di Kabupaten Wonogiri. Selain itu, hasil penelitian ini dapat memperkecil risiko kerugian dalam pelaksanaan proyek yang dialami oleh kontraktor. 
Penelitian hanya dilakukan terhadap Penyedia Jasa Konstruksi yang telah melakukan atau melaksanakan proyek jalan di Kabupaten Wonogiri tahun 2017 dan 2018. Penelitian hanya meninjau faktor pelaksanaan proyek yang menjadi penyebab pembengkakan biaya pada Rencana Anggaran Proyek (RAP) kontraktor. Pengambilan data dilakukan dengan metode seleksi kepada kontraktor dengan grade M1 dan M2. Dari hasil seleksi tersebut, didapat 68 kontraktor dari 88 proyek. Sampel diambil dari banyaknya proyek, bukan banyaknya kontraktor. Hal ini dikarenakan walaupun kontraktor sama, tetapi perbedaan proyek dapat menyebabkan masalah pembengkakan biaya yang berbeda.

Pembengkakan biaya pada pekerjaan jalan di Wonogiri dapat dikategorikan cukup signifikan. Hal ini terjadi karena penyelesaian proyek jalan di Wonogiri melampaui waktu direncanakan. Selain itu, dimungkinkan juga karena pengaturan lapangan yang kurang dimanajemen dengan cermat. Manajemen adalah suatu proses untuk memanfaatkan sumber daya manusia dan sumber daya lainnya untuk mencapai tujuan tertentu (Sahid, 2017).

Semakin besar suatu proyek, semakin ketat anggaran dan waktunya, maka semakin besar pula kemungkinan munculnya masalah-masalah. Walaupun masalah yang muncul bisa diperkirakan namun yang pasti tetap ada masalah yang masih muncul secara tak terduga (Davidson, 2002).

Meskipun kegiatan direncanakan sebaik mungkin, pasti akan tetap mengalami keadaan di mana pelaksanaan tidak berjalan sesuai rencana. Hal yang mengakibatkan kerugian harus dipertimbangkan dengan baik. Jika tidak ditangani sebaik mungkin, maka akan menimbulkan masalah yang berdampak buruk pada suatu proyek (Dipohusodo, 1996).

Pembengkakan biaya di suatu proyek konstruksi tersebut terjadi pada 3 (tiga) waktu yang dijelaskan seperti berikut ini (Soeharto, 1997).

a. Pembengkakan biaya saat awal proyek konstruksi.

b. Pembengkakan biaya pada saat pelaksanaan proyek konstruksi.

c. Pembengkakan biaya setelah proyek konstruksi. Walaupun proyek telah selesai, kontraktor masih memiliki tanggung jawab yang tidak bisa selesai begitu saja.

Kegiatan estimasi adalah kegiatan untuk memperkirakan berapa besar dana yang harus disiapkan untuk membuat bangunan. Apabila perkiraan biaya tidak tepat, maka akan menimbulkan dampak pada pihak-pihak yang terllibat di dalamnya (Ervianto, 2002).
Hal-hal yang mempengaruhi biaya konstruksi terdapat pada aktivitas dan kegiatan seperti produktivitas tenaga kerja, ketersediaan material dan peralatan, cuaca, jenis kontrak, masalah kualitas, etika, sistem pengendalian.

\section{METODOLOGI}

Metode penelitian survei merupakan penelitian yang sumber data dan informasi utamanya didapatkan dari responden. Sampel dari hasil survei ini digunakan sebagai sumber data primer. Penentuan sampel minimum menggunakan teori Slovin (1960) berdasarkan rumus sebagai berikut:

$$
n=\frac{N}{1+N e^{2}}
$$

Keterangan :

$\mathrm{n}$ = sampel minimal

$\mathrm{N}=$ populasi

$\mathrm{e}=$ nilai error margin

Data yang digunakan pada penelitian ini adalah data primer dan data sekunder. Diawali dengan mengumpulkan beberapa data risiko yang menyebabkan pembengkakan biaya yang sudah terjadi pada pelaksanaan proyek jalan di Kabupaten Wonogiri yang menggunakan APBD. Adapun data yang menyebabkan pembengkakan biaya yaitu: estimasi biaya, pelaksanaan dan hubungan kerja, aspek dokumen, material, tenaga kerja, peralatan, keuangan proyek, waktu dan pelaksanaan, dan pengaturan lapangan. Metode analisis data menggunakan analisis regresi linier berganda. Pengolahan data dibantu menggunakan aplikasi SPSS Versi 25. Variabel dependen dalam laporan ini adalah $(Y)$, sedangkan variabel independen yaitu $\left(X_{I}\right)$ sampai dengan $\left(X_{9}\right)$. Selanjutnya data risiko tersebut diidentifikasi, hasil dari identifikasi tersebut dideskripsikan dan dipetakan ke dalam faktor penyebab utama terjadinya cost overrun.

Data primer diperoleh langsung dari sumber asli, dalam hal ini diperoleh dari responden yaitu kontraktor yang telah melaksanakan proyek jalan di Kabupaten Wonogiri pada tahun 2017 dan 208. Data primer didapatkan dari wawancara dan hasil dari kuesioner. Ketika wawancara, cara mengumpulkan data dilakukan sebagai berikut.

a. Mengumpulkan data penyebab terjadinya pembengkakan biaya dari berbagai literatur.

b. Melakukan wawancara responden atau objek penelitian kepada ahli di satuan kerja yang ada dalam Ditjen Bina Marga untuk dimintai keterangan tentang sumber penyebab terjadinya pembengkakan biaya.

c. Mengelola dan melakukan analisa data hasil wawancara. 
Data sekunder didapatkan secara tidak langsung yaitu melalui perantara. Data sekunder pada penelitian ini merupakan data yang didapatkan dari Dinas Pekerjaan Umum dan Ditjen Bina Marga yang berupa daftar nama-nama kontraktor yang menangani proyek jalan di Kabupaten Wonogiri dari tahun 2017 dan 2018.

Survei pada penelitian ini menggunakan kuesioner dalam bentuk angket tertutup, yaitu angket yang berisi pertanyaan dengan disajikan beberapa jawaban untuk dipilih responden sesuai dengan keadaan pribadinya. Penilaian pada kuesioner menggunakan skala Likert yaitu jawaban responden dinilai dengan skala 1 sampai dengan 5 . Adapun maksud dari skala tersebut adalah 1 untuk sangat tidak setuju, 2 untuk tidak setuju, 3 untuk ragu-ragu, 4 untuk setuju, dan 5 untuk sangat setuju.

Survei yang dilakukan adalah menyebar kuesioner kepada kontraktor yang menangani proyek jalan di Kabupaten Wonogiri pada tahun 2017 dan 2018. Kontraktor yang menangani proyek ini tidak hanya berada di Wonogiri, namun juga dari luar wilayah Wonogiri. Misalnya ada yang dari Semarang, Yogyakarta, dan Jawa Timur. Namun, mayoritas kontraktor yang menangani adalah dari Kabupaten Wonogiri itu sendiri.

Ketika mengumpulkan data, terdapat beberapa data yang belum lengkap. Data tersebut yaitu ada beberapa poin kuesioner yang belum diisi oleh responden, sehingga harus menanyai kembali agar data tersebut menjadi lengkap dan akurat. Selain itu, ada juga kuesioner yang tidak kembali. Hal ini dikarenakan beberapa kontraktor memang tidak mau mengisi kuesioner semacam ini dengan alasan memiliki privasi. Tentunya ini sangat dimaklumi karena perusahaan pastinya juga memiliki aturan tertentu.

Wilayah Wonogiri kuesioner disebar secara langsung tanpa melalui perantara, namun untuk kontraktor yang berada di Jawa Timur kuesionernya dikirim melalui kurir karena keterbatasan peneliti untuk menyerahkan ke daerah tersebut. Apabila semua data terkumpul langkah berikutnya adalah analisis. Pada proses analisis data dibantu dengan aplikasi SPSS Versi 25.

Menurut Algifari (2000), model regresi yang diperoleh dari metode kuadrat terkecil biasa (Ordinary Least Squares/OLS). Model regresi ini menghasilkan estimator linier tidak bias yang terbaik (Best Linier Unbias Estimator/BLUE). Kondisi ini akan terjadi jika dipenuhi beberapa asumsi yang disebut asumsi klasik, diantaranya sebagai berikut.
a. Uji normalitas
b. Uji Heteroskedastisitas
c. Uji multikoliniearitas

Langkah pada penelitian dapat dilihat dalam Gambar 1.

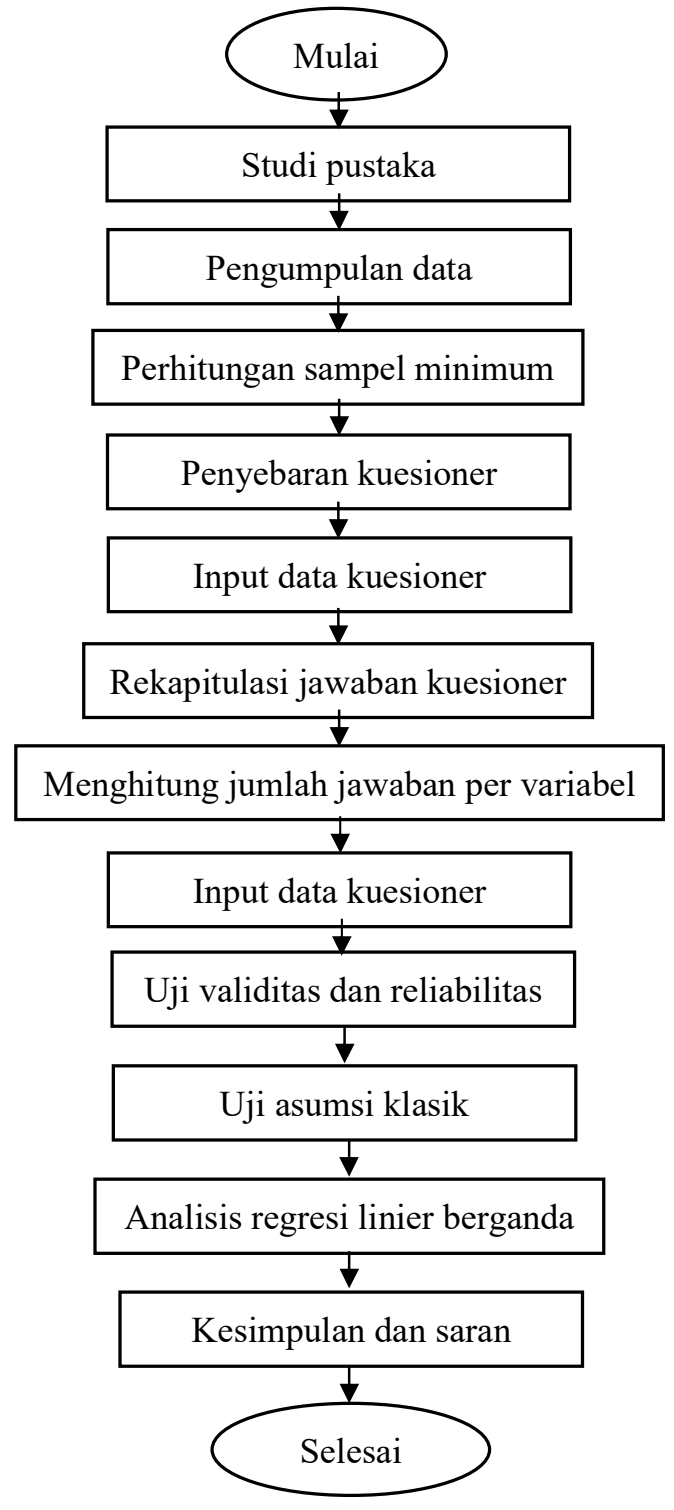

Gambar.1 Bagan alir penelitian

\section{HASIL DAN PEMBAHASAN}

Analisis pada penelitian ini adalah pendekatan penelitian kuantitatif, yaitu menggunakan data berupa angka-angka. Data kuantitatif terdiri dari Pembengkakan Biaya pada Proyek Jalan di Kabupaten Wonogiri (Y), Estimasi Biaya $\left(X_{I}\right)$, Pelaksanaan dan Hubungan Kerja $\left(X_{2}\right)$, Aspek Dokumen $\left(X_{3}\right)$, Material $\left(X_{4}\right)$, Tenaga Kerja $\left(X_{5}\right)$, Peralatan $\left(X_{6}\right)$, Keuangan Proyek $\left(X_{7}\right)$, Waktu dan Pelaksanaan $\left(X_{8}\right)$, Pengaturan Lapangan $\left(X_{9}\right)$ (Ramdani, 2013). Metode analisis data menggunakan analisis regresi linier berganda. Pengolahan data dibantu menggunakan aplikasi SPSS Versi 25. Variabel dependen dalam laporan ini adalah $(Y)$, sedangkan variabel independen yaitu $\left(X_{1}\right)$ sampai dengan $\left(X_{9}\right)$. 


\subsection{Pengujian Validitas}

Syarat data dikatakan valid adalah dengan

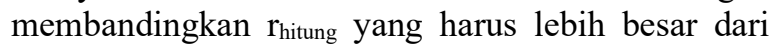
$\mathrm{r}_{\text {tabel }}$ yaitu 0,2242 (dari tabel $\mathrm{r}$ ).

Berdasarkan pengujian validitas maka ada tiga item pernyataan yang tidak valid yaitu X2.2, X3.2, X3.3 (Sub-variabel), sehingga ketiga item pernyataan tersebut dihilangkan atau dihapus. Selain tiga item pernyataan tersebut, semuanya valid.

\subsection{Pengujian Reliabilitas}

Sujarweni (2014) menjelaskan bahwa apabila uji reliabilitas dilakukan secara serentak terhadap semua pertanyaan pada kuesioner akan reliabel jika koefisien Cronbach's Alpha lebih besar dari 0,6 (Tabel 1).

Tabel 1. Reliabilitas

\begin{tabular}{cc}
\hline Cronbach's Alpha & $\mathrm{N}$ of Items \\
\hline, 950 & 36 \\
\hline
\end{tabular}

Berdasarkan dari pengujian reliabilitas didapatkan nilai Cronbach's Alpha adalah 0,950 $(>0,6$ maka semua pernyataan reliabel).

\subsection{Pengujian Asumsi Klasik}

Uji asumsi klasik harus dilakukan karena pada model regresi perlu memperhatikan penyimpanganpenyimpangan atas asumsi klasik, karena pada dasarnya apabila asumsi klasik tidak terpenuhi maka variabel-variabel yang menjelaskan menjadi tidak efisien.

\subsubsection{Uji Normalitas}

Dari Gambar 2, dapat dikatakan bahwa distribusi histogram mengikuti distribusi normal. Untuk lebih meyakinkan karena perbedaan visualisasi dalam pandangan, maka dapat dilihat dari grafik Normal PP Plot of Regression Standardized (Gambar 3).

Data berpencar di sekitar garis lurus miring melintang sehingga dapat dikatakan bahwa asumsi normal terpenuhi (Gambar 3). Untuk lebih akurat lagi, dilakukan pengujian hipotesis melalui Uji Kolmogorov-Smirnov (Tabel 2). Berdasarkan Tabel 2, $p_{\text {value }}$ uji Kolmogorov-Smirnov adalah 0,081. Karena $p_{\text {value }}$ dari uji Kolmogorov-Smirnov $>$ dari $\alpha(0.05)$, maka $H_{0}$ diterima artinya error berdistribusi normal terpenuhi.

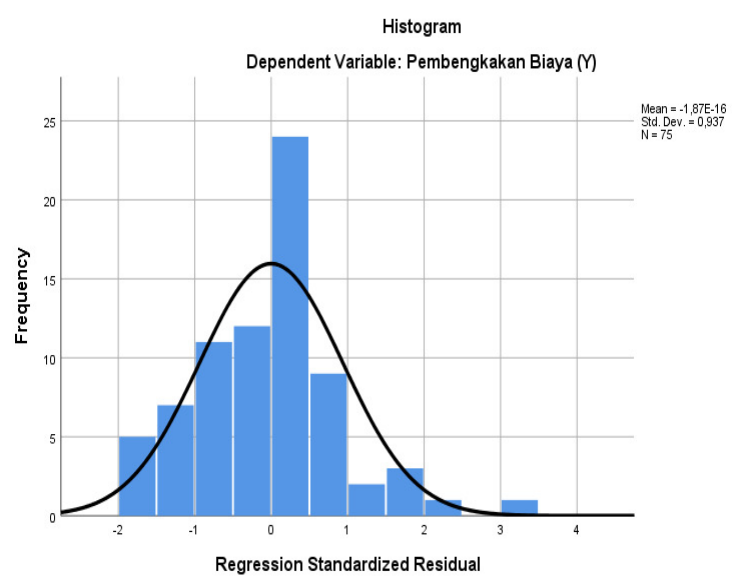

Gambar 2. Diagram Histogram Normallitas

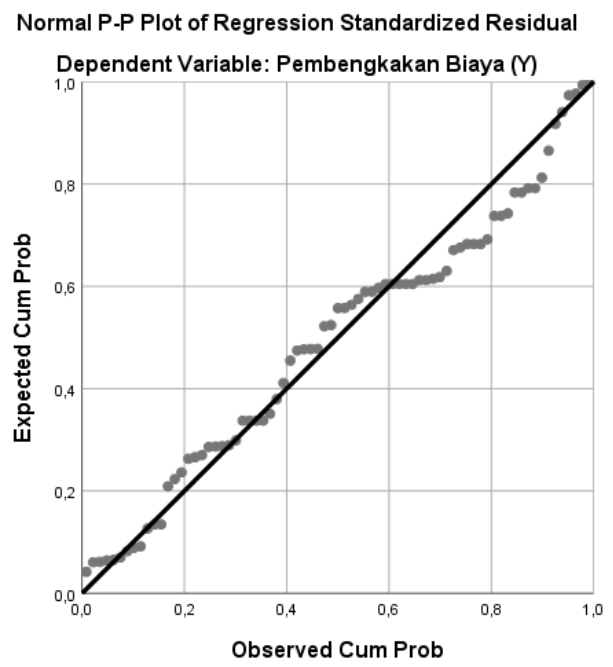

Gambar 3. Normal PP Plot of Regression Standardized

Tabel 2. Uji Kolmogorov-Smirnov

\begin{tabular}{|c|c|c|}
\hline & & Unstandardized Residual \\
\hline $\mathrm{N}$ & & 75 \\
\hline \multirow[t]{2}{*}{ Normal Parameters ${ }^{\mathrm{a}, \mathrm{b}}$} &, 0000000 & 0,0000000 \\
\hline & ,13386273 & 0,13386273 \\
\hline \multirow[t]{3}{*}{ Most Extreme Differences } &, 070 & 0,070 \\
\hline &, 070 & 0,070 \\
\hline &,- 041 & $-0,041$ \\
\hline Test Statistic & &, 096 \\
\hline Asymp. Sig. (2-tailed) & & $081^{\mathrm{c}}$ \\
\hline
\end{tabular}

\subsubsection{Uji Heteroskedastisitas}

Dilihat dari Gambar 4, data membentuk pola acak (tidak membentuk corong atau tidak membentuk suatu pola), mengindikasikan bahwa variansi sisaan konstan sehingga dapat disimpulkan tidak ada heteroskedastisitas. 


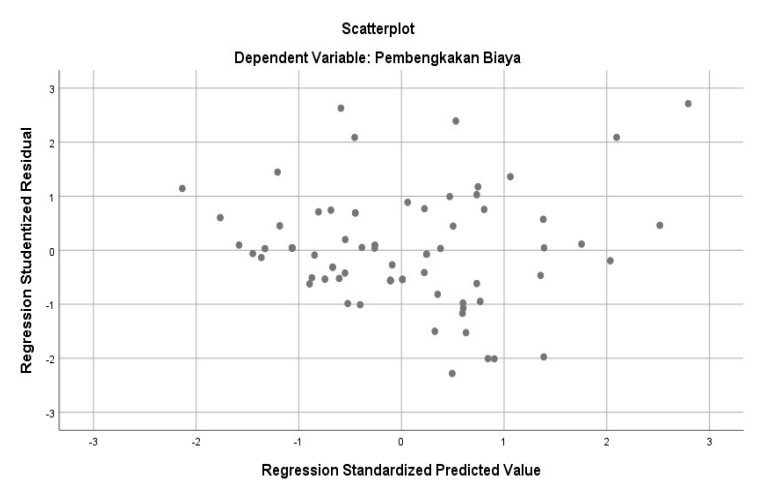

Gambar 4. Scatterplot Error

\subsubsection{Uji Multikolinearitas}

Uji multikolinearitas dapat dilihat dari nilai VIF dan tolerance (Tabel 3). Terjadi multikolinearitas apabila nilai $V I F>10$ dan nilai Tolerance $<$ 0,1. Berdasarkan hasil pada Tabel 3, dapat dilihat bahwa nilai VIF untuk semua variabel $\mathrm{X}_{1}-\mathrm{X}_{9}$ adalah lebih kecil dari 10 dan nilai Tolerance $<0,1$, maka dapat disimpulkan bahwa tidak terdapat adanya multikolinearitas.

Tabel 3. Coefficients

\begin{tabular}{|c|c|c|c|c|c|c|c|c|}
\hline \multirow[b]{2}{*}{ Mod } & & \multicolumn{2}{|c|}{$\begin{array}{l}\text { Unstandardized } \\
\text { Coefficients }\end{array}$} & \multirow{2}{*}{$\begin{array}{l}\text { Standardized } \\
\text { Coefficients } \\
\text { Beta }\end{array}$} & \multirow[b]{2}{*}{$\mathrm{t}$} & \multirow[b]{2}{*}{ Sig. } & \multirow{2}{*}{\multicolumn{2}{|c|}{$\begin{array}{cr}\text { Collinearity } & \text { Statistics } \\
\text { Tolerance } & \text { VIF }\end{array}$}} \\
\hline & & $\mathrm{B}$ & Std. Error & & & & & \\
\hline \multirow[t]{10}{*}{1} & (Constant) &,- 109 &, 346 & &,- 315 &, 754 & & \\
\hline & $\mathrm{X} 1$ &, 031 &, 024 & ,274 & 1,307 & , 196 & ,233 & 4,287 \\
\hline & $\mathrm{X} 2$ & ,024 & ,036 & , 195 & ,669 & ,506 &, 121 & 8,286 \\
\hline & $\mathrm{X} 3$ &,- 116 & , 087 &,- 223 & $-1,343$ &, 184 & ,372 & 2,685 \\
\hline & $\mathrm{X} 4$ &,- 036 &, 027 &,- 299 & $-1,310$ & , 195 & , 197 & 5,067 \\
\hline & $\mathrm{X} 5$ &,- 015 &, 039 &,- 073 &,- 382 & ,703 & ,283 & 3,535 \\
\hline & $\mathrm{X} 6$ &, 039 &, 024 & ,283 & 1,612 &, 112 & ,334 & 2,998 \\
\hline & X7 &,- 019 &, 043 &,- 068 &,- 438 & ,663 &, 425 & 2,351 \\
\hline & $\mathrm{X} 8$ &, 033 &, 037 &, 150 &, 894 &, 374 & ,366 & 2,734 \\
\hline & X9 &, 121 &, 048 & ,351 & 2,521 &, 014 &, 531 & 1,882 \\
\hline
\end{tabular}

\subsection{Pengujian Statistik Analisis Regresi}

\subsubsection{Uji Signifikansi Simultan (Uji F)}

Uji $\mathrm{F}$ menunjukkan seberapa besar pengaruh variabel independen secara bersama-sama terhadap variabel dependen. Hasil regresi semua variabel $\mathrm{X}$ terhadap Y (Pembengkakan Biaya Proyek Jalan di Kabupaten Wonogiri tahun 2017 dan 2018), dengan menggunakan taraf kepercayaan 95\% $(\alpha=5 \%)$ dapat dilihat dalam Tabel 4.

Tabel 4. ANOVA

\begin{tabular}{ccccccc}
\hline Model & $\begin{array}{c}\text { Sum of } \\
\text { Squares }\end{array}$ & df & $\begin{array}{c}\text { Mean } \\
\text { Square }\end{array}$ & F & Sig. \\
\hline \multirow{2}{*}{1} & Regression & 9,517 & 9 & 1,057 & 3,589 &, $001^{\mathrm{b}}$ \\
\cline { 2 - 7 } & Residual & 19,150 & 65 &, 295 & & \\
\cline { 2 - 7 } & Total & 28,667 & 74 & & & \\
\hline
\end{tabular}

Berdasarkan hasil output diatas, diperoleh $p_{\text {value }}$ sebesar 0,001 . Karena $p_{\text {value }}=0,001<\alpha=0,05$, maka $H_{0}$ ditolak artinya terdapat satu variabel independen yang berpengaruh signifikan terhadap Pembengkakan Biaya Proyek Jalan di Kabupaten Wonogiri.

\subsubsection{Uji Signifikansi Parameter Individual (Uji t)}

Uji t bertujuan untuk mengetahui apakah variabel dependen $(X)$ secara parsial (sendiri-sendiri) berpengaruh terhadap variabel dependen $(Y)$, dengan hipotesa dan taraf signifikansi sebagai berikut: i. $H_{0}: \beta_{1}=0$ (Variabel $\mathrm{X}$ tidak berpengaruh signifikan terhadap $\mathrm{Y})$.

$H_{1}: \beta_{1} \neq 0$ (Variabel $\mathrm{X}$ berpengaruh signifikan terhadap Y)

ii. Taraf signifikansi $\alpha=0,05$

iii. Daerah Kritis: $H_{0}$ ditolak jika $p_{\text {value }}<\alpha=$ 0,05

iv. Selain menggunakan nilai signifikan juga bisa membandingkan nilai $t_{\text {tabel }}$ dengan $t_{\text {hitung, }}$, apabila $t_{\text {hitung }}>t_{\text {tabel }}$ maka variabel tersebut berpengaruh signifikan. dengan melihat tabel $t$, maka didapatkan nilai $t_{\text {tabel }}$ sebesar 1,997.

Berdasarkan Tabel 5, dapat disimpulkan bahwa Pengaturan Lapangan berpengaruh signifikan terhadap Pembengkakan Biaya karena nilai $p_{\text {value }}=$ $0,014<\alpha=0,05$ dan nilai $\mathrm{t}_{\text {hitung }}=2,521>\mathrm{t}_{\text {tabel }}=$ 1,997 .

\subsection{Uji koefisien determinasi $\left(R^{2}\right)$}

Dari Tabel 6, dihasilkan nilai $R$-squared sebesar 0,332. Berarti besarnya pengaruh variabel $\mathrm{X}$ terhadap variabel $\mathrm{Y}$ yang dapat dijelaskan oleh regresi adalah sebesar $33,2 \%$ dan sisanya $66,8 \%$ merupakan pengaruh yang tidak dapat dijelaskan oleh regresi tersebut. Bisa jadi karena faktor-faktor lain. 
Tabel 5. Hasil Uji t

\begin{tabular}{lccccc}
\hline \multicolumn{1}{c}{ Variabel } & $\alpha$ & $p_{\text {value }}$ & tabel & thitung & Keterangan \\
\hline Estimasi Biaya & 0,05 & 0,196 & 1,997 & $-0,315$ & TBS \\
\hline Pelaksanaan dan Hubungan Kerja & 0,05 & 0,506 & 1,997 & 1,307 & TBS \\
\hline Aspek Dokumen & 0,05 & 0,184 & 1,997 & 0,669 & TBS \\
\hline Material & 0,05 & 0,195 & 1,997 & $-1,343$ & TBS \\
\hline Tenaga Kerja & 0,05 & 0,703 & 1,997 & $-1,310$ & TBS \\
\hline Peralatan & 0,05 & 0,112 & 1,997 & $-0,382$ & TBS \\
\hline Keuangan Proyek & 0,05 & 0,663 & 1,997 & 1,612 & TBS \\
\hline Waktu dan Pelaksanaan & 0,05 & 0,374 & 1,997 & $-0,894$ & TBS \\
\hline Pengaturan Lapangan & 0,05 & 0,014 & 1,997 & 2,521 & BS \\
\hline $\begin{array}{l}\text { Keterangan: } \\
\text { TBS Tidak Berpengaruh Signifikan }\end{array}$ & & & & \\
BS = Berpengaruh Signifikan & & & & &
\end{tabular}

Tabel 6. Koefisien Determinasi

\begin{tabular}{ccccc}
\hline Model & $\mathrm{R}$ & $\begin{array}{c}\mathrm{R} \\
\text { Square }\end{array}$ & $\begin{array}{c}\text { Adjusted } \\
\text { Square }\end{array}$ & $\begin{array}{c}\text { Std. Error of } \\
\text { the Estimate }\end{array}$ \\
\hline 1 &, $576^{\mathrm{a}}$ &, 332 &, 239 &, 543 \\
\hline
\end{tabular}

\subsection{Persamaan regresi linier berganda}

Persamaan regresi linier berganda yang didapat adalah sebagai berikut:

$$
\begin{aligned}
(Y)= & -0,109+0,031(X 1)+0,024(X 2)- \\
& 0,116(X 3)-0,036(X 4)-0,015(X 5)+ \\
& 0,039(X 6)-0,019(X 7)+0,033(X 8)+ \\
& 0,121(X 9)
\end{aligned}
$$

dengan:

$$
\begin{array}{ll}
\mathrm{Y} & =\text { Pembengkakan Biaya } \\
\mathrm{X} 1 & =\text { Estimasi Biaya } \\
\mathrm{X} 2 & =\text { Pelaksanaan dan Hubungan Kerja } \\
\mathrm{X} 3 & =\text { Aspek Dokumen } \\
\mathrm{X} 4 & =\text { Material } \\
\mathrm{X} 5 & =\text { Tenaga Kerja } \\
\mathrm{X} 6 & =\text { Peralatan } \\
\mathrm{X} 7 & =\text { Keuangan Proyek } \\
\mathrm{X} 8 & =\text { Waktu Pelaksanaan } \\
\mathrm{X} 9 & =\text { Pengaturan Lapangan }
\end{array}
$$

Pada persamaan tersebut terdapat tanda negatif atau tanda positif, hal ini menyatakan bahwa apabila tanda positif maka hubungan variabel $\mathrm{X}$ dengan $\mathrm{Y}$ berbanding lurus, sedangkan apabila bertanda negatif maka berbanding terbalik. Artinya penambahan pada variabel X yang bertanda positif akan menyebabkan penambahan juga pada variabel Y. Sedangkan apabila penambahan pada variabel $\mathrm{X}$ yang bertanda negatif akan menyebabkan penurunan pada variabel $Y$.

Berdasarkan hasil persamaan regresi tersebut, diperoleh nilai koefisien Estimasi Biaya $\left(X_{l}\right)=$ 0,031 dan bertanda positif, menyatakan bahwa bentuk hubungan antara Estimasi Biaya terhadap Pembengkakan Biaya Proyek Jalan adalah berbanding lurus yang berarti bahwa peningkatan faktor Estimasi Biaya sebesar 1 satuan akan meningkatkan Pembengkakan Biaya Proyek Jalan di Kabupaten Wonogiri sebesar 0,031.

Nilai koefisien Pelaksanaan dan Hubungan Kerja $\left(X_{2}\right)=0,024$ dan bertanda positif, menyatakan bahwa bentuk hubungan antara Pelaksanaan dan Hubungan Kerja terhadap Pembengkakan Biaya Proyek Jalan adalah berbanding lurus yang berarti bahwa peningkatan faktor Pelaksanaan dan Hubungan Kerja sebesar 1 satuan akan meningkatkan Pembengkakan Biaya Proyek Jalan di Kabupaten Wonogiri sebesar 0,024.

Nilai koefisien Aspek Dokumen $\left(X_{3}\right)=-0,116$ dan bertanda negatif, menyatakan bahwa bentuk hubungan antara Aspek Dokumen terhadap Pembengkakan Biaya Proyek Jalan adalah berbanding terbalik yang berarti bahwa peningkatan faktor Aspek Dokumen sebesar 1 satuan akan menurunkan Pembengkakan Biaya Proyek Jalan di Kabupaten Wonogiri sebesar 0,116.

Nilai koefisien Material $\left(X_{4}\right)=-0,036$ dan bertanda negatif, menyatakan bahwa bentuk hubungan antara Material terhadap Pembengkakan Biaya Proyek Jalan adalah berbanding terbalik yang berarti bahwa peningkatan faktor Material sebesar 1 satuan akan menurunkan Pembengkakan Biaya Proyek Jalan di Kabupaten Wonogiri sebesar 0,036.

Nilai koefisien Tenaga Kerja $\left(X_{5}\right)=-0,015$ dan bertanda negatif, menyatakan bahwa bentuk hubungan antara Tenaga Kerja terhadap Pembengkakan Biaya Proyek Jalan adalah berbanding terbalik yang berarti bahwa peningkatan faktor Tenaga Kerja sebesar 1 satuan akan menurunkan Pembengkakan Biaya Proyek Jalan di Kabupaten Wonogiri sebesar 0,015.

Nilai koefisien Peralatan $\left(X_{6}\right)=0,039$ dan bertanda positif, menyatakan bahwa bentuk hubungan antara Peralatan terhadap Pembengkakan Biaya Proyek Jalan adalah berbanding lurus yang 
berarti bahwa peningkatan faktor Peralatan sebesar 1 satuan akan meningkatkan Pembengkakan Biaya Proyek Jalan di Kabupaten Wonogiri sebesar 0,039.

Nilai koefisien Keuangan Proyek $\left(X_{7}\right)=-0,019$ dan bertanda negatif, menyatakan bahwa bentuk hubungan antara Keuangan Proyek terhadap Pembengkakan Biaya Proyek Jalan adalah berbanding terbalik yang berarti bahwa peningkatan faktor Keuangan Proyek sebesar 1 satuan akan menurunkan Pembengkakan Biaya Proyek Jalan di Kabupaten Wonogiri sebesar 0,019.

Nilai koefisien Waktu dan Pelaksanaan $\left(X_{8}\right)=$ 0,033 dan bertanda positif, menyatakan bahwa bentuk hubungan antara Waktu dan Pelaksanaan terhadap Pembengkakan Biaya Proyek Jalan adalah berbanding lurus yang berarti bahwa peningkatan faktor Waktu dan Pelaksanaan sebesar 1 satuan akan meningkatkan Pembengkakan Biaya Proyek Jalan di Kabupaten Wonogiri sebesar 0,033.

Nilai koefisien Pengaturan Lapangan $\left(X_{9}\right)=$ 0,121 dan bertanda positif, menyatakan bahwa bentuk hubungan antara Pengaturan Lapangan terhadap Pembengkakan Biaya Proyek Jalan adalah berbanding lurus yang berarti bahwa peningkatan faktor Pengaturan Lapangan sebesar 1 satuan akan meningkatkan Pembengkakan Biaya Proyek Jalan di Kabupaten Wonogiri sebesar 0,121.

\subsection{Perhitungan besarnya pembengkakan biaya yang terjadi pada proyek jalan di Wonogiri}

Berdasarkan frekuensi jawaban dari responden sebagai parameter dalam menentukan besarnya pembengkakan biaya pada proyek jalan di Wonogiri disajikan pada Tabel 7.

Tabel 7. Analisis Distribusi Frekuensi Pembengkakan Biaya Proyek

\begin{tabular}{cc}
\hline Besar Pembengkakan Biaya (\%) & Frekuensi \\
\hline $1 \%-5 \%$ & 44 \\
\hline $6 \%-10 \%$ & 28 \\
\hline $11 \%-15 \%$ & 2 \\
\hline $16 \%-20 \%$ & 1 \\
\hline Total & 75 \\
\hline
\end{tabular}

Dari Tabel 7, dapat disimpulkan bahwa kontraktor yang mengalami pembengkakan biaya sebesar $1 \%-5 \%$ ada 44 responden, lalu untuk pembengkakan biaya $6 \%-10 \%$ ada 28 responden, dan $11 \%-15 \%$ ada 2 responden, serta $16 \%-20 \%$ hanya 1 responden saja.

\section{KESIMPULAN}

Pengaturan lapangan berpengaruh signifikan terhadap pembengkakan biaya karena memenuhi persyaratan yaitu $\mathrm{p}_{\text {value }}=0,014<\alpha=0,05$ dan nilai $\mathrm{t}_{\text {hitung }}=2,521>\mathrm{t}_{\text {tabel }}=1,997$, sehingga dapat disimpulkan bahwa penyebab pembengkakan biaya pada proyek jalan di Kabupaten Wonogiri tahun
2017 dan 2018 adalah faktor pengaturan lapangan. Apabila diurutkan dari yang paling tinggi adalah karena kurangnya penyediaan fasilitas pendukung lapangan (X9.2), dan karena keterbatasan luas area proyek (X9.1). Selain faktor pengaturan lapangan tidak ada yang berpengaruh signifikan terhadap pembengkakan biaya.

Faktor dominan yang menyebabkan pembengkakan biaya pada proyek jalan di Kabupaten Wonogiri adalah kurangnya penyediaan fasilitas pendukung lapangan, dan berdasarkan analisis jawaban dari responden dapat disimpulkan bahwa kontraktor yang mengalami pembengkakan biaya sebesar 1\%-5\% ada 44 responden, lalu untuk pembengkakan biaya $6 \%-10 \%$ ada 28 responden, dan $11 \%-15 \%$ ada 2 responden, serta $16 \%-20 \%$ hanya 1 responden saja.

Dalam penelitian ini berarti terdapat paling tidak satu faktor yang mengakibatkan pembengkakan biaya, sehingga hipotesis dilakukannya penelitian ini diterima. Hasil penelitian ini hanya berlaku di daerah Wonogiri saja karena lingkup penelitian ini adalah di Wonogiri. Sehingga apabila data ini digunakan sebagai acuan di daerah lain tidak akan akurat. Untuk penelitian selanjutnya, mungkin bisa diteliti lebih spesifik lagi agar hasilnya bisa lebih akurat.

\section{REFERENSI}

Ahmad, Z., B. Anigbogu, N. A., \& Molwus, J. J. (2018). Peculiarities of Road Projects Cost Overruns. International Journal of Scientific and Engineering Research, 9(6), 121-124.

Algifari (2000). Analisis Regresi (Edisi 2). Yogyakarta: BPFE.

Davidson, J. (2002). Manajemen Proyek. Yogyakarta: Andi.

Dipohusodo, I. (1996). Manajemen Proyek dan Konstruksi. Yogyakarta: Kanisius.

Ervianto, W. I. (2002). Manajemen Proyek Konstruksi. Yogyakarta: Andi Offset.

Love, P. E. D., Sing, M. C. P., Carey, B., \& Kim, J. T. (2015). Estimating Construction Contingency: Accommodating the Potential for Cost Overruns in Road Construction Projects. American Society of Civil Engineers, 04014035, 1-10.

Priyastama, R. (2017). Buku Sakti Kuasai SPSS. Yogyakarta: Start Up.

Ramdani, D. (2013). Analisis Faktor Penyebab Pembengkakan Biaya (Cost Overrun) pada Proyek Konstruksi Tugas Akhir Yogyakarta: Fakultas Teknik, Universitas Atma Jaya.

Sahid, M. N. (2017). Teknik Pelaksanaan Konstruksi Bangunan. Surakarta: Muhammadiyah University Press.

Soeharto, I. (1997). Manajemen Proyek dari Konseptual sampai Operasional. Jakarta: Erlangga.

Sujarweni, V. W. (2014). Metode Penelitian: Lengkap, Praktis, dan Mudah Dipahami. Yogyakarta: Pustaka Baru Press.

Venkateswaran, C. B. \& Rajiah M. (2017). Time Delay and Cost Overrun of Road over Bridge (ROB) Construction Projects in India, Journal of Construction in Developing Countries, 22(1), 79-96). 